\title{
Exploration of Macro-Economic Theory of New Open Economy
}

\author{
Danlin Li \\ Jilin Business and Technology College, Jilin, China \\ 16205918@qq.com
}

Keywords: New Open Economy Macroeconomics, Nominal Short Term Rigidity

\begin{abstract}
With the rapid development of the world economy, the destabilizing factors of the world economy are also becoming more and more significant. As the focus of economics research field, open economy macroeconomics is admitted to the foreign has a significant effect on its economy at the same time, also in unceasing explore open economy's influence on the effectiveness of monetary policy. The new open economy macroeconomics is the inheritance and extension of the previous research orientation and research concept, which is a comprehensive exposition based on the framework of the model creation.
\end{abstract}

\section{Introduction}

Western countries have been the focus of macroeconomic research, because western capitalist economies rely more on economic predictability. In today's economic globalization, the increasingly close economic and trade relationship between countries in the world, for each local country, foreign influence on local economy market are quietly and continually expanding. New open economy macroeconomics research is standing on the basis of the theory, the traditional Keynesian framework, using the commonly used way of modeling, macroeconomics in microeconomic and macroeconomic variables of individual relevance, such as monetary policy research.

\section{Research direction and achievements of traditional open economy macroeconomics}

\subsection{Research Model Of Traditional Open Economy Macroeconomics}

Traditional open economy macroeconomics is based on the generation of new open economy macroeconomics point, until the $1950 \mathrm{~s}$ open economy macroeconomics analysis is using the method of standing in the short-term behavior of flexible exchange rates, the ' $60 \mathrm{~s}$ appeared after the corresponding modeling method. Mathematical modeling of an open economy macroeconomics research way is better to petty and small problem in the process of research on mathematical model of data, combined with a certain analysis method to the final research conclusion. The research model of macroeconomics of traditional open economy has m-f model, m-f-d model and Lucas model. These three economic research models are produced in different economic situations, and the development of macroeconomics of open economy is landmark research significance. The focus of the model is different from the emphasis on the influence of international capital flows on exchange rate and internal and external policies under the effect of market equilibrium interest rate. Mr. Dornbush summed up the important economic phenomenon of exchange rate overtones; finally, in the monetary view of Lucas, the unexpected fluctuations in the actual economy of the money supply change. The research in the field of open economy macroeconomics is this kind of constant bottleneck, innovation development, initial model and overturning improvement. On the basis of this, the author insists that theoretical studies combine practical effects to adapt to the latest development of the world economic situation, timely change variables and bring out new ones in a timely manner. 


\subsection{Effectiveness of Traditional Monetary Policy}

Whether it is the direction of economic research or not, the theoretical study of any expert scholar is not independent from reality, especially in economics. So in the real life of economic activity, all the relevant personnel of the essence of the most obvious feeling is economic factor of liquidity is much stronger than the physical mobility, this principle is the flow of the market, is also active market factors. But the study of macroeconomics, know to feel the flow of this situation is not the ultimate goal, but to find the essential question, investigate its fundamental after to reverse the countermeasure research. The currently existing in open economy macroeconomics is pointed out that the adjustment of financial and economic market speed is much faster than the commodity market adjust speed, which is the flow status of fundamental problem. Traditional monetary policy analysis and exchange rate system selection are based on capital controls under the flexible exchange rate system, in order to reduce the exchange rate fluctuations caused by currency shock. And the effectiveness of traditional monetary policy is the behavioral finance theory and the theory of portfolio rebalancing the comprehensive elaboration, but this does not represent the effectiveness of the traditional monetary create model can solve all problems. The dynamic changes in current accounts cannot be explained for individual accounts, and the utility of government projects is unexplainable for government organizations.

\section{Research direction and achievements of new open economy macroeconomics}

\subsection{Nominal Short-Term Rigidity and Price Stickiness}

Nominal rigidity is generally nominal term rigidity, which is actually nominal viscosity, but the nominal price stickiness is the most common problem in macroeconomics research. This is because the nominal variables including commodity prices and wages are monetary level variable factors, but each country to meet consumer demand, the expansionary monetary policy will have different, price stickiness related problem also emerges. Because of the different problems, is not to say that with a gay, general can solve even the most vendors for a period of viscous pricing, but the reality of the economic market will leap and die pricing operating problems. A large part of the reason for nominal price viscosity is the deterioration in terms of trade due to the short-term rigidity. The commodity price stickiness can directly affect the domestic exchange rate, and the correlation is clear. The correlation between exchange rate, import and export commodity prices and domestic trade conditions is direct and severe. The hit market economy will show some problems at a certain time, short or long term. Such macroeconomic in nominal rigidities is important to note that combining menu cost is a basic condition, consider the market demand is a necessary condition, the price stickiness is to deal with conditions, finally the implementation of the goal is to reduce exogenous shock in real economic activity, ensure the accuracy and rationality.

\subsection{Research Model of New Open Economy Macroeconomics}

From the perspective of macroeconomics, the current research model of macroeconomics of new open economy mainly adopts Redux model. The prominent significance of this model is the creator will economic market monopoly competition and the nominal price stickiness in dynamic equilibrium model, such not only can solve the problem of the main price stickiness nominal short-term rigidity, will also be able to solve the theoretical research of static defects from the model itself. Under the new open economy macroeconomics, a scientific research model does not mean the end of the early work, but also to the use of model under the conditions of the way for the selection of reasonable. Based on the research of Redux model, the corresponding expert scholars mainly adopt the hypothetical research, and explore different solutions through the hypothesis of several big problems. The conditions of the hypothesis are the subject of economy, the stickiness of nominal price, and trade barriers between countries, international transaction costs and government financing. Of the existing research results, of course, did not make the research process of new open economy macroeconomics stuck in the past, in today's global economy has been merged together, to adapt to the present state of the economy, to realize economic basis decision factors involved, the superstructure strength reserve force is the country's economic strength, with such cognition is to let the study of new open economy macroeconomics is big, gigantic realistic significance. 


\subsection{Market Segmentation}

Although the process of economic globalization is accelerating and the world economy is constantly converging, trade barriers still exist in the present international trade. Importers and exporters of international trade are discriminating against commodity prices in different national markets, namely discriminatory pricing in business terms. Discrimination pricing is not, but it is the research direction of open economy macroeconomics, the study in Redux model of integration into the international market segmentation and market pricing is good research results. The performance of market segmentation can be reflected in the pricing of commodities, which involves the change of consumption demand between the two countries and the fluctuation of the international exchange rate. Market pricing will be in a certain extent, ignored the international exchange rate influence on commodity prices, may lead to differences between countries to reduce the consumption of common changes, limits of the country's terms of trade and international welfare.

\subsection{Consumption Preference and Domestic Preference}

Consumer preferences and domestic favor assumes that the restricted areas of the biggest different is different, the specific performance in the assumption of consumer preference is domestic residents of consumers for domestic and foreign goods with the same consumer preferences; The domestic preference assumes that domestic consumers spend more on domestic products than foreign ones. However, whether the preference is assumed to be the consumption preference or the domestic preference, the research method adopted is the micro basic research under the open economic model. In fact, we should realize that as long as the consumption preference for individuals is elastic, and the momentum is very obvious, after all, personal consumption will not be able to come to an end. The hypothesis of preference hypothesis is that the flexible change of personal consumption is fully realized, so the preference hypothesis is more detailed and the study is based on the hypothesis analysis. But constantly is the kind of default preferences assumes that the final is in the study of the role of the international monetary union, came to the conclusion that the situation of the international monetary union in either a preference assumption is superior to national monetary policy system of competition.

\section{Conclusion}

Economic globalization is a new opportunity and challenge to open economy macroeconomics. New open economy macroeconomics research is combined with the actual, strive for more realistic model is established in this paper, through the establishment of more strict assumptions and control, to expect to be able to better serve the society research conclusion. The new opening economic macroeconomics is reflected in the fundamental change of the research framework, the scientific modeling on the micro basis, the increasing of various variables, and the integration of government policies. As the focus of mainstream macroeconomics research, the accumulation of research experience and the exploration of in-depth research are the corresponding fields.

\section{References}

[1] "New open economy macroeconomics" development review,[J].Sheng Wang,Hengpu Zou,Financial research,2006(01)

[2] New open economy macroeconomics: theory and problem,[J]. Duoduo Shang, The world economy,2009(09) 